\title{
The Use of Smart Technologies in the Professional Training of Students of the Law Departments for the Development of their Critical Thinking
}

\author{
Igor M. Kopotun \\ Academia HUSPOL, \\ Hranice, Czech Republic \\ Myroslav Yu. Durdynets \\ Department of Philosophy of Law and Legal Logic, National Academy of \\ Internal Affairs, Kyiv, Ukraine \\ Nina V. Teremtsova \\ Department of Theory of Law and State, Law Faculty, Taras Shevchenko \\ National University of Kyiv, Kyiv, Ukraine \\ Lidiia L. Markina \\ Department of Psychology and Pedagogy, Dnipropetrovsk State University of \\ Internal Affairs, Dnipro, Ukraine \\ Luidmila M. Prisnyakova \\ Department of Psychology and Pedagogy, Dnipropetrovsk State University of \\ Internal Affairs, Dnipro, Ukraine
}

\begin{abstract}
The objective of this study was to find out how effective the use of smart technologies is in the professional training of students of the law departments, in particular for the formation and development of their critical thinking. According to the author, the combination of the potential of smart technologies in learning and the development of critical thinking in students allows the most optimal solution of the contradictions between the needs of a modern society and the current practice of professional training of students, in particular, students of the law departments. The experimental model with the use of smart technologies was tested in the academic courses "Intellectual Property and Copyright" and "Fundamentals of Administrative Law", which are part of the special subjects of the educational and professional training program for students of the Speciality 081: Law. In order to analyze the results obtained and the efficiency ratio of the experimental model against the traditional model and STATA Software was applied. The study showed the efficiency of the use of smart technologies in the formation and development of critical
\end{abstract}


thinking in future lawyers. The author concluded that the use of smart technologies in the professional training of students of the law departments also facilitates feedback, which increases students' learning motivation and allows monitoring of changes in student development. This model can be applied to teaching other subjects in both full-time and distance learning.

Keywords: SMART education; Innovative educational technologies; Smart technologies; Critical thinking; Professional training of specialists

\section{Introduction}

The analysis of researches and publications shows that the subject of active search of Ukrainian and foreign scholars is theoretically grounded standardization of the conceptual framework of the problem under study (Cademia \& Kobisia, 2016; Singh \& Miah, 2020), the advantages of ubiquitous learning over traditional forms of organization of the educational process (Kearney, Burden \& Schuck, 2019), pedagogical conditions for improving the quality of professional training of future specialists (Isaienko \& Kushmar, 2016; Borawska-Kalbarczyk, Tołwińska $\&$ Korzeniecka-Bondar, 2019). Comprehensive research into the problem of using innovative learning environments in the context of informatization was conducted by Korsunska (2013). Dychkivska (2013) consider smart technologies as innovative pedagogical technologies in her works. Glazunova (2013) focuses on the study of innovative approaches to the organization of school education, and Solomko (2013) - on the use of innovative technologies in the conditions of modern higher education. Krasylnyk (2013) explores individual aspects of the use of information technologies in the process of teacher training. Zeer (2010), Pozdnyakov (2012), Tykhomyrov (2011), Tikhomirova (2012) and others work on the development of issues of quality assurance of professional training and development of necessary abilities of using smart technologies. Ways of applying smart technologies and their adaptation to the use in the educational environment are analyzed in publications (Bonch-Bruevych, Abramov \& Kosenko, 2007; Yakubov \& Yakinin, 2011; Vasylenko \& Kyrda, 2014). However, the problem of the use of smart technologies in the process of professional training of specialists is still not well studied.

We believe that the effective way of overcoming the contradictions between the needs of modern society and the current system of training specialists is the transition to a new educational paradigm where the main role belongs to the person, and to the widespread use of smart technologies in the process of professional training in higher educational institutions. The spread of personal computers arose the idea of engaging them for the acquisition of knowledge and skills, and the concept of e-learning emerged in scientific works (Bonch-Bruevych et al., 2007; Rosenberg, 2005; van Seters, Ossevoort, Tramper \& Goedhart, 2012; Uskov et al., 2016). The search of scholars has led to the emergence of blended learning concepts (Arbaugh, Desai, Rau \& Sridhar, 2010), mobile learning (mlearning) (Moore, 2000; Ahn \& Lee, 2016), ubiquitous learning (u-learning) (Kim, 2008; Alsheail, 2010; Gros, Kinshuk \& Maina, 2016) and seamless learning (Chan et al., 2006). Currently, the term "smart education" means organized interaction of all subjects of the educational process, which aims at forming systemic multi- 
dimensional vision of the subject of studied science in students, and is carried out through technical innovations and the Internet (Hwang, Yang \& Kim, 2010; Zhu, Yu \& Riezebos, 2016). All concepts are united by the understanding that now learning and innovative technologies (smart technologies) form a mutually predetermined model of technology-enhanced learning that is accessible to a student in time and space (Spector \& SLFG, 2018).

In our study, we consider smart technologies as:

"a set of innovative technical means of designing an educational and
developmental environment of a higher educational institution, aimed at
ensuring systemic realization of educational goals and comprehensive
mastering of the content of professional training, as well as introduction
of appropriate forms, methods, techniques with significant developmental
potential into the educational practice" (Dychkivska, 2013, p. 29).

On the present stage of development of higher education in Ukraine we consider the idea of using digital manuals in the educational process (Joo \& Lim, 2015) and that of applying widely smart-technologies in the practice of professional training of a competitive specialist (OECD, 2018) to be extremely interesting and highly promising.

The statement of Zhang and $\mathrm{Lu}$ (2008), that a special role in the system of results of smart education is given to cognitive competence when forming a complex vision of the problem, the ability to see complex structures of phenomena, causes of their occurrence, alternatives, to give their own judgment, to defend their point of view etc. Zhang and Lu (2008) has become another cornerstone of our study, as such understanding is closely related to our understanding of the role of critical thinking in professional training of future professionals. The problem of the development of critical thinking is extremely urgent because the task of the modern high school is to prepare a specialist who is able to use knowledge in practice, critically evaluate the achievements and seek ways of self-improvement (Holdsworth \& Thomas, 2016; The Ontario Public Service, 2016).

Different aspects of the introduction of computer information technology into the educational process have been considered in the works of many domestic and foreign authors, however, the issue of the use of smart technologies in higher education has not been studied enough.

The above identified the choice of the topic of our study, which was to identify the degree of efficiency of the use of smart technologies in the formation and development of critical thinking in future lawyers.

\section{Research Methods}

This quantitative study was conducted in four stages, using general scientific theoretical, empirical and statistical methods. In order to determine the levels of formation of critical thinking in the future lawyers by means of smart technologies in the process of professional training, students were offered various diagnostic methods, taking into account the structure of the phenomenon under study. Thus, the level of the development of the motivational and value component of future lawyers was determined by means of a questionnaire survey: "Studying the 
Motives of Students' Educational Activities" (Badmaeva, 2004). Data on the manifestation of the cognitive component in future lawyers were obtained through testing: "Determining the Level of Students' Knowledge and Results of Students' Achievements" (author's development). The level of the development of the activity component of future lawyers by means of smart technologies was determined by means of questionnaire survey: "Diagnosis of the Level of Mastering Personal Computer and Internet Resources" (Fedoruk, 2014). Data on the manifestation of the communicative component in future lawyers was determined through testing: "Assessment of Communicability and Organizational Skills" (Fetiskin, Kozlov \& Manuilov, 2012). The level of the development of personal component in future lawyers through smart technologies was determined using the author's diagnostic test: "Questionnaire Aimed at Identifying the Existing Level of Innovative Culture of Future Lawyers".

\subsection{Research Design}

The study was prolonged and was conducted in four stages: 1) preparatory; 2) summative; 3) formative; 4) final. The research design is presented in Figure 1.

Preparatory stage: study and analysis of scientific sources on the problem; substantiation of reasonability of the use of smart technologies in educational activity; development of an experimental model using e-guides for the courses on Intellectual Property and Copyright and Fundamentals of Administrative Law; selection of diagnostic tools

Summative stage: forming a valid study sample; conducting a summative experiment; processing of obtained data

Experimental stage: conducting a formative experiment with the use of electronic manuals on the training courses "Intellectual Property and Copyright" and "Fundamentals of Administrative Law"; collecting and processing the data obtained

Final stage: interpretation of statistical indicators; comparison of the results obtained with those expected; development of recommendations

Figure 1: Research design

Two training courses "Intellectual Property and Copyright" and "Fundamentals of Administrative Law" were selected for conducting the experiment after interviewing 408 students of Bachelor programs in speciality 081 "Law" of the Khmelnytsky University of Management and Law, Chernihiv National Technological University, State University of Infrastructure and Technologies (Kyiv) and the Academy of Labour, Social Relations and Tourism (Kyiv). An important factor in the choice was the availability of digital manuals for the specified training courses, the ability to use smart board by teachers when delivering lecture material, access to Internet resources and the ability to connect 
to the network of students' personal gadgets in classrooms or libraries (reading rooms). Lecture materials (in the form of video lectures and lecture notes), as well as instructional materials for practical and seminar classes were developed and / or modified by the instructors of the courses "Intellectual Property and Copyright" and "Fundamentals of Administrative Law", integrated into online manuals on the iSpring platform. This platform enables students to use the materials of the online manuals to independently develop the academic content of the training courses.

During the preparatory stage of the study, the following components and indicators for the development of critical thinking (cognitive competence) of lawyers in the application of smart technologies were identified during the development of an experimental model using iSpring platform-based digital manuals for the courses (Intellectual Property and Copyright; Fundamentals of Administrative Law): motivational and value component (the level of development of professional interests in the field of law; positive attitude to theoretical and practical training; interest in continuing professional development); cognitive (deep knowledge of the theory of law; mastering of innovative research technologies; innovative legal thinking; variability of legal thinking); activity (ability to receive, store, process, transfer and present information with the help of modern devices and technologies; ability and skills to work on a personal computer using operating systems which are adequate to the set tasks, etc.); communicative (ability to clearly express and reason their opinions, build evidence; skills to analyze and establish interpersonal relationships; ability to choose the best style of communication, organize and maintain dialogue); personal (understanding of the social significance and value of the professional activity of the future lawyer; the level of development of professionally necessary qualities, including responsibility, organization, independence, honesty, sociability; formation of value attitude to health).

The motivational criterion is determined by the criterion for the development of the motivational and value component of cognitive competence of future lawyers, general-scientific - cognitive, information-computer - activity, social communicative and self-regulating - personal. These components and indicators have become a prerequisite for identifying the high, medium and low levels of critical thinking in future lawyers by means of smart technologies.

\subsubsection{Sampling}

At the preparatory stage, $4082^{\text {nd }}$-year bachelor students of the speciality 081: Law' and 14 teachers of higher educational institutions (Khmelnytsky University of Management and Law, Chernihiv National Technological University, State University of Infrastructure and Technology (Kyiv), Academy of Labour, Social Relations and Tourism (Kyiv)) were involved in this study The total number of participants was $n=422$ people. A valid sample calculator was used to determine the representative sample. The sample was 50 people for total of $n=422$ people. The experimental (EG) and control (CG) groups were formed taking into account the indicated number. The experimental group (EG) consisted of 25 people; the control group (CG) had the same number of persons (25). The comparative analysis was carried out within existing academic groups by model programs. In 
the control groups, professional training was carried out according to standard methods, and in experimental groups - according to the method where the critical thinking in the future lawyers was formed by means of smart technologies.

At the summative stage, students of the control and experimental groups were diagnosed according to the questionnaires and tests determined in the methodological framework of the study to establish the initial levels of the development of components of critical thinking (cognitive competence) in students. The data obtained during the summative experiment are presented in Table 1.

Table 1: The level of development of critical thinking in students of experimental and control group (summative stage)

\begin{tabular}{|c|c|c|c|}
\hline \multirow{2}{*}{$\begin{array}{l}\text { Groups } \\
\text { (number of } \\
\text { people) }\end{array}$} & \multicolumn{3}{|c|}{ Levels of development } \\
\hline & high & medium & low \\
\hline \multicolumn{4}{|c|}{ I According to the criterion of the motivational and value component developmer } \\
\hline EG (25) & $4.00 \%(1)$ & $32.00 \%(8)$ & $64.00 \%(16)$ \\
\hline CG (25) & $4.00 \%(1)$ & $28.00 \%(7)$ & $68.00 \%(17)$ \\
\hline \multicolumn{4}{|c|}{ II According to the criterion of the cognitive component development } \\
\hline EG (25) & --- & $28.00 \%(7)$ & $72.00 \%(18)$ \\
\hline CG (25) & --- & $32.00 \%(8)$ & $68.00 \%(17)$ \\
\hline \multicolumn{4}{|c|}{ III According to the criterion of the activity component development } \\
\hline EG (25) & $20.00 \%(5)$ & $32.00 \%(8)$ & $48.00 \%(12)$ \\
\hline CG (25) & $24.00 \%(6)$ & $28.00 \%(7)$ & $48.00 \%(12)$ \\
\hline \multicolumn{4}{|c|}{ IV According to the criterion of the communicative component developmen } \\
\hline EG (25) & $16.00 \%(4)$ & $72.00 \%(18)$ & $12.00 \%(3)$ \\
\hline CG (25) & $8.00 \%(2)$ & $84.00 \%(21)$ & $8.00 \%(2)$ \\
\hline \multicolumn{4}{|c|}{$V$ According to the criterion of the personal component development } \\
\hline EG (25) & $12.00 \%(3)$ & $52.00 \%(13)$ & $36.00 \%(9)$ \\
\hline CG (25) & $8.00 \%(2)$ & $52.00 \%(13)$ & $40.00 \%(10)$ \\
\hline
\end{tabular}

Thus, according to the criterion of the motivational and value component development in both the experimental and the control group, the highest proportion was students with low levels $(64 \%$ and $68 \%$, respectively). Approximately one third of students showed medium level $(32 \%$ and $28 \%$, respectively). A high level of motivation development was identified in students, which accounted for $4 \%$ of the total number of respondents. According to the 
criterion of the cognitive component development, the vast majority of students in both groups showed low (experimental group - 72\%; control group - 68\%) and medium level of the component development (28\% and $32 \%$, respectively); no students with high levels of cognitive development have been identified. According to the criterion of the activity component development, slightly less than half of the students made up the share with the low level of development of the specified component ( $48 \%$ in both groups); the proportion of students with a medium level of component development was $32 \%$ in the experimental group and $28 \%$ in the control group. Other students were diagnosed with a high level of development of the activity component - 20\% (experimental group) and 24\% (control group). According to the criterion of the communicative component development in both groups, the highest proportion was students with an average level of development of this characteristic (experimental group - 72\%; control group - 84\%). However, the low level of the component development was found in $12 \%$ of the students of the experimental group, and there was only was only $8 \%$ of such students in the control group. There is a different picture regarding the high level of communication component development: it is $16 \%$ in the experimental group of students and only $8 \%$ in the control group. According to the criterion of personal component development, about forty percent of students showed low level of development (experimental group - 36\%; control group $40 \%$ ); the proportion of students with a medium level of personal component development was the same (52\%); high level of personal component development was shown by $12 \%$ of students of the experimental group and $8 \%$ of students of the control group.

As we can see, at the initial stage of the study, the characteristics of the experimental and control groups are quite different, but they are quite comparable.

\subsubsection{Tools for collecting and processing statistics}

Quantitative methods were used to accomplish the research objectives, in particular such as: test results performed by students from both groups; questionnaires for students and teachers; focus group survey to determine the impact factor of the proposed training organization model. The following methods were used to analyze the quantitative data: Chi-Square statistical method and triangulation (Zulfiqar \& Bhaskar, 2016; STATA Software, n.d.). To analyze the responses of the focus group participants to determine the categorical framework of the study, we used the online tool - Text Analyzer, following the guidelines for conducting research in focus groups (OMNI, n.d.; Krueger \& Casey, 2000; Onwuegbuzie, Dickinson, Leech \& Zoran, 2009).

\section{Results}

After conducting a pedagogical experiment on the use of smart technologies for the development of critical thinking in students (future lawyers), repeated measurements were made according to the same determined diagnostic questionnaires and tests. Their results are shown in Table 2. Comparison of the indicators of the summative and formative stages of the experiment shows that positive changes have taken place in all components of the critical thinking 
development in the lawyers of both the experimental and control groups (see Table 2).

Table 2: Critical thinking development in students of experimental and control group (experimental stage)

\begin{tabular}{|c|c|c|c|}
\hline \multirow{2}{*}{$\begin{array}{l}\text { Groups } \\
\text { (number of } \\
\text { people) }\end{array}$} & \multicolumn{3}{|c|}{ Levels of development } \\
\hline & high & medium & low \\
\hline \multicolumn{4}{|c|}{ I According to the criterion of the motivational and value component developmen } \\
\hline EG (25) & $20.00 \%(5)$ & $60.00 \%(15)$ & $20.00 \%(5)$ \\
\hline CG (25) & $8.00 \%(2)$ & $52.00 \%(13)$ & $40.00 \%(10)$ \\
\hline \multicolumn{4}{|c|}{ II According to the criterion of the cognitive component development } \\
\hline EG (25) & $12.00 \%(3)$ & $48.00 \%(12)$ & $40.00 \%(10)$ \\
\hline CG (25) & $8.00 \%(2)$ & $44.00 \%(11)$ & $48.00 \%(12)$ \\
\hline \multicolumn{4}{|c|}{ III According to the criterion of the activity component development } \\
\hline EG (25) & $28.00 \%(7)$ & $52.00 \%(13)$ & $20.00 \%(5)$ \\
\hline CG (25) & $24.00 \%(6)$ & $44.00 \%(11)$ & $32.00 \%(8)$ \\
\hline \multicolumn{4}{|c|}{ IV According to the criterion of the communicative component development } \\
\hline EG (25) & $20.00 \%(5)$ & $72.00 \%(18)$ & $8.00 \%(2)$ \\
\hline CG (25) & $12.00 \%(3)$ & $84.00 \%(21)$ & $4.00 \%(1)$ \\
\hline \multicolumn{4}{|c|}{$V$ According to the criterion of the personal component development } \\
\hline EG (25) & $24.00 \%(6)$ & $64.00 \%(16)$ & $12.00 \%(3)$ \\
\hline CG (25) & $16.00 \%(4)$ & $56.00 \%(14)$ & $28.00 \%(7)$ \\
\hline
\end{tabular}

However, the greatest "shifts" were noted in those students who, by the level of development of different components, belonged to the proportion with a low level at the beginning of the experiment. According to Criterion I, the proportion of students with low levels of motivation "lost" from 28 to 44 percent; according to Criterion II - from 20 to 32 percent; according to Criterion III - from 16 to 28 percent; according to Criterion IV - 4 percent; according to Criterion V - from 12 to 24 percent. The proportion of students who were diagnosed with the medium level of the development of each component during the formative experiment underwent fewer quantitative changes compared to the summative experiment, but it should be remembered that part of the students with a predetermined medium level became a source of positive shifts for the proportion of students with a high level of development of individual components, as well as students with a predetermined low level (summative experiment) "fed" the proportion of 
students with medium levels of the development of components after the formative pedagogical experiment.

\subsection{Limitations of the study}

The main limiting factors of this study are the short time spent on the implementation of the experimental phase ( $1^{\text {st }}$ semester, i.e. 15 weeks), the specialization of students, the heterogeneous level of students' skills of using gadgets and the teachers' readiness to use existing smart technologies in the teaching process.

\section{Discussion}

For a more visual comparison of the results of the study, we will apply the method of determining the efficiency of the experimental model for each of the components of the critical thinking development in lawyers.

According to Dychkivska (2013), the efficiency ratio of the model, which is tested experimentally, is calculated by the formulas:

$$
K e=(B e( \pm) \Delta B): B k ; \Delta B=B k^{\prime}-B e^{\prime}
$$

where

$B e^{\prime}$ - is the mean score of the object of diagnosis "a" of the experimental group before the forming experiment;

$B k^{\prime}$ - is the mean score of the object of diagnosis " $a$ " of the control group before the forming experiment;

$B e$ - is the mean score of the object of diagnosis " $a$ " of the experimental group after the forming experiment;

$B k$ - is the mean score of the object of diagnosis " $a$ " of the control group after the forming experiment.

Moreover, if $K e>1$, then the efficiency of the experimental model is higher than the control one, if $K_{e}<1$, the efficiency of the experimental model is lower than the control one, if $K_{e}=1$, the efficiency of both models is the same. The mean scores of each of the objects of diagnosis (motivational and value component, cognitive component, activity component, communication component, personal component) were calculated by IBM SPSS Statistics 25.0.0.1. software. The results of the calculations are presented in Table. 3.

Table 3: The efficiency ratios of the proposed model of the development of components of critical thinking in students of experimental and control groups

\begin{tabular}{|l|c|}
\hline \multicolumn{1}{|c|}{ Object of diagnosis } & Efficiency ratio $\mathrm{K}_{\mathrm{e}}$ \\
\hline I Motivational and value component development & 1,1489 \\
\hline II Cognitive component development & 1,1184 \\
\hline III Activity component development & 1,0764 \\
\hline IV Communicative component development & 1,0064 \\
\hline V Personal component development & 1,0792 \\
\hline
\end{tabular}


The results obtained on the efficiency of the use of smart technologies in the professional training of lawyers to develop their critical thinking require some explanation and comparison with the expected results of the study. Although the experimental model has proven to be more effective compared to traditional techniques across all objects of diagnosis (ratios are higher than 1), the experimental data indicate that the use of smart technologies in the professional training of lawyers has the greatest impact on the formation and development of motivations and values (motivational and value component) and assimilation of knowledge by the students (cognitive component). In general, such "leading" characteristics of these components are not unexpected: many studies claim that smart technologies have a significant impact on the development of motivation, a positive attitude to learning, the formation of deep theoretical knowledge, etc. (Minchekar, 2017). The development of personal and activity components is second, according to our results. If the slightly more modest results of the experiment on the personal component can be explained by the objective psychological characteristics of personality formation (it takes some time to change personal stereotypes and gain new ones; these timescales are wider than the period of our experiment), the results of the experiment on the activity component were lower than we expected. A possible explanation is that students' level of information competence was different, students had to expand their computer skills, and sometimes to master unfamiliar ways of processing and transferring information using a computer and other gadgets (mastering new operations also take some time). The slowest pace of development of the communicative component was quite unexpected. One of the explanations for this result is the lack of logical and linguistic training of students. However, in order to make more confident conclusions, an additional analysis of the current situation is needed.

Teaching by traditional technologies does not fully contribute to the motivation for learning of students who are already accustomed to the use of traditional learning technologies in the educational processes. At the same time, developing a strong motivation for student learning is one of the most important aspects of improving the quality of professional training in the global educational space. The use of innovative methods or at least their elements is of interest, encourages students to try their hand, involves active exchange of experience and ideas, leads to "subjectivization" of learning depending on its tasks and competences, saves much time on revision of already available educational material. In order to develop strong motivation for learning, the teacher should be able to recognize students' reactions, provide timely feedback, and apply, as far as possible, an individual approach. Our research has shown that these tasks often cause difficulties for teachers, and sometimes psychological opposition. However, teachers who are open to innovation understand that the use of Smarttechnologies in the training of future professionals provides ample opportunity for effective learning and further personal development, and subsequently for increasing competencies at any stage of training.

The conducted research revealed a number of side results, namely: the need to find a higher education institution with the proper material and technical base 
and insufficient training of teachers to use the full range of various opportunities of smart technologies in the educational process in higher educational institutions. There are, undoubtedly, positive moments pointed out by both students and teachers involved in the experiment: in the conditions of using digital educational technologies it becomes impossible to miss a class or to fail to fulfill the task because of a missed class; smart technologies make it possible to effectively organize team work of students in class and independent work out-of-class; allow you to individualize the learning process and to modernize practical lessons.

\section{Conclusions}

The study showed the effectiveness of the use of smart technologies in the formation and development of critical thinking in future lawyers. The most significant influence of the use of smart technologies in the process of professional training of lawyers is revealed

- in the high level of the development of students' professional interests in the field of law, a positive attitude to theoretical and practical training;

- in deepening the knowledge of the theory of law, mastering innovative technologies of research by students;

- in mastering the ability to obtain, store, process, transfer and present information using modern devices and technologies; skills of work on the personal computer with the use operating systems which are adequate to the task set, etc.

- in improving students' ability to express and reason clearly their opinions, build evidence, analyze and make connections;

- in understanding the social significance and value of the professional activity of the future lawyer, the formation of professionally necessary qualities, including responsibility, organization, independence, sociability.

An important factor in the effective use of smart technologies in the professional training of lawyers is the creation of feedback that promotes student motivation; organization of the availability of an array of educational materials for shared or individual use; integrating individual educational resources and making them more user-friendly; monitoring of constant changes in the development of new technologies. Thus, the use of smart technologies changes the nature of the interaction between lecturers and students (the role of the student in the process of his professional training increases, and the lecturer becomes the coordinator of the educational process). This model can be adapted for teaching other subjects in both "full-time" and distance learning in order to improve professional training of specialists.

\section{References}

Ahn, T. Y., \& Lee, S. M. (2016). User experience of a mobile speaking application with automatic speech recognition on for EFL learning. British Journal of Educational Technology, 47(4), 778-786. https://doi.org/10.1111/bjet.12354

Alsheail, A. (2010). Teaching English as a Second/Foreign Language in a Ubiquitous Learning Environment: A Guide for ESL/EFL Instructors (Master thesis). California State University, Chico, CA. 
Arbaugh, J. B., Desai, A., Rau, B., \& Sridhar, B. S. (2010). A review of research on online and blended learning in the management disciplines: 1994-2009. Organization Management Journal, 7(1), 39-55.

Badmaeva, N. (2004). The influence of the motivational factor on the development of mental abilities: monograph. Ulan-Ude, Russia: Publishing House of VSTU.

Bonch-Bruevych, G. F., Abramov, V. O., \& Kosenko, T. I. (2007). Methods of applying SMART Board technology in the learning process: textbook. Kyiv, Ukraine: B. D. Grinchenko KMPU.

Borawska-Kalbarczyk, K., Tołwińska, B., \& Korzeniecka-Bondar, A. (2019). From Smart Teaching to Smart Learning in the Fast-Changing Digital World. In L. Daniela (Ed.), Didactics of Smart Pedagogy (pp. 23-39). Cham, Switzerland: Springer.

Cademia, M. Y., \& Kobisia, W. M. (2016). Distance Learning Technologies: Glossary. Vinnytsia, Ukraine: IE Tarnashynskyi O. V.

Chan, T.-W., Roschelle, J., Hsi, S., Kinshyk, K., Sharples, M., Brown, T., ... Hoppe, U. (2006). One-to-one technology-enhanced learning: an opportunity for global research collaboration. Research and Practice in Technology Enhanced Learning, 1(1), 3-29.

Dychkivska, I. M. (2013). Innovative pedagogical technologies: Workshop: textbook. Kyiv, Ukraine: Slovo.

Fedoruk, G. M. (2014). State of information and communication competence of future technology teachers. Proceedings of the all-Ukrainian conference of young scientists: Sociology - social work - regulation of social problems (pp. 142-145). Lviv, Ukraine: Lviv Polytechnic Publishing House.

Fetiskin, N. P., Kozlov, V. V., \& Manuilov, G. M. (2012). Socio-psychological diagnosis of the development of personality and small groups. Moscow, Russia: Publishing House of the Institute of Psychotherapy.

Glazunova, O. G. (2013). SMART approach to e-learning course design in MOODLE. Retrieved from http://2013.moodlemoot.in.ua/course

Gros, B., Kinshuk, \& Maina, M. (2016). The future of ubiquitous learning. Learning designs for emerging pedagogies. Heidelberg, Germany: Springer.

Holdsworth, S., \& Thomas, I. (2016). A sustainability education academic development framework (SEAD). Environmental Education Research, 22(8), 1073-1097.

Hwang, D. J., Yang, H-K., \& Kim, H. (2010). E-Learning in Republic Korea. Moscow, Russia: UNESCO Institute for Information Technologies in Education.

Isaienko, S., \& Kushmar, L. (2016). Professional culture formation in students: negative factors to be eliminated. Humanitarian Bulletin, 36(Suppl. 1), 102-111.

Joo, Y. J., \& Lim, E. (2015). Factors influencing learners' satisfaction of using digital textbooks in a middle school science class. Research Institute of Curriculum Instruction, 19(2), 239-257. http://dx.doi.org/10.24231/rici.2015.19.2.239

Kearney, M., Burden, K., \& Schuck, S. (2019). Disrupting Education Using Smart Mobile Pedagogies. In L. Daniela (Ed.), Didactics of Smart Pedagogy (pp. 139157). Cham, Switzerland: Springer.

Kim, K. (2008). Ubiquitous Learning Supporting System for Future Classroom in Korea. In K. McFerrin, R. Weber, R. Carlsen, D. Willis (Eds.), Proceedings of SITE 2008 Society for Information Technology \& Teacher Education International Conference (pp. 2648-2657). Las Vegas, Nevada: Association for the Advancement of Computing in Education (AACE).

Korsunska, L. M. (2013). Korean smart education concept: general education, digital smart-school manuals. Education and Development of Gifted Personality, 11, 77-80. 
Krasylnyk, Y. S. (2013). Information technologies as a factor of intensifying the preparation of a future teacher in terms of magistracy. Retrieved from http://lib.iitta.gov.ua/2986/1/Стат_Красильник_2013.pdf

Krueger, R. A., \& Casey, M. A. (2000). Focus groups: A practical guide for applied researchers (3rd ed.). Thousand Oaks, CA: Sage.

Minchekar, V. S. (2017). The Role of Cognitive Style in Creative Thinking among College Students. Psychology and Behavioral Science International Journal, 6(1), 555679. http:/ /dx.doi.org/10.19080/PBSIJ.2017.06.555679

Moore, M. G. (2000). Theory of Transactional Distance. In D. Keegan (Ed.) Theoretical Principles of Distance Education (pp. 22-39). New York, NY: Routledge.

OECD. (2018). Teaching for the future: Effective classroom practices to transform education. Retrieved from http://www.oecd.org/education/school/teaching-for-thefuture-9789264293243-en.htm

OMNI. (n.d.). Toolkit for Conducting Focus Groups. Retrieved from https://www.nyla.org/max/userfiles/Documents/D._Focus_Group_Toolkit.p df

Onwuegbuzie, A. J., Dickinson, W. B., Leech, N. L., \& Zoran, A. G. (2009). A Qualitative Framework for Collecting and Analyzing Data in Focus Group Research. International Journal of Qualitative Methods, 8(3), 1-21.

Pozdnyakov, V. A. (2012). Practical realization of the adaptive subsystem of ensuring quality of training of pedagogical staff on the basis of the cloud computing technology. Pedagogical Education in Russia, 6, 70-75.

Rosenberg, M. J. (2005). Beyond E-Learning: New Approaches to Managing and Delivering Organizational Knowledge. Retrieved from https://performancevision.com/step/webinars/STEPBeyondE-LearningHandout062105.pdf

Singh, H., \& Miah, S. J. (2020). Smart education literature: A theoretical analysis. Education and Information Technologies. https://doi.org/10.1007/s10639-020-10116-4

Solomko, M. T. (2013). The use of digital technology education in the training of students of pedagogical skills. Updating the content, forms and methods of education and upbringing in educational institutions: Collection of scientific papers. Scientific notes of Rivne State Humanities University, 7(50), 187-194.

Spector, J. M., \& SLFG (The Smart Learning Futures Group). (2018). Smart learning futures: a report from the $3^{\text {rd }}$ US-China smart education conference. Smart Learning Environments, 5, 5. https:/ / doi.org/10.1186/s40561-018-0054-1

STATA Software. (n.d.). Retrieved from https://www.stata.com/

The Ontario Public Service. (2016). 21 ${ }^{\text {st }}$ century competencies. Phase 1: Towards Defining 21st Century Competencies for Ontario. Foundation document for discussion. Retrieved from

http://www.edugains.ca/resources21CL/About21stCentury/21CL_21stCentur yCompetencies.pdf

Tikhomirova, N. V. (2012). Global smart society development strategy. MESI on the way to Smart University. Retrieved from http:/ / smartmesi.blogspot.com/2012/03/smart-smart.html

Tykhomyrov, V. P. (2011). The world on the way to Smart Education: new opportunities for development. Open Education, 3, 22-28.

Uskov, V. L., Bakken, J. P., Pandey, A., Singh, U., Yalamanchili, M., \& Penumatsa, A. (2016). Smart University Taxonomy: Features, Components, Systems. In V. Uskov, R. Howlett, \& L. Jain (Eds.), Smart Education and e-Learning 2016. Smart Innovation, Systems and Technologies, vol 59. Cham, Switzerland: Springer. https://doi.org/10.1007/978-3-319-39690-3_1 
van Seters, J. R., Ossevoort, M. A., Tramper, J., \& Goedhart, M. J. (2012). The influence of student characteristics on the use of adaptive e-learning material. Computers $\mathcal{E}$ Education, 58, 942-952.

Vasylenko, S. V., \& Kyrda, A. V. (2014). Smart notebook as an ICT way for development of research competence. Information Technologies and Learning Tools, 3(41), 142-150.

Yakubov, S., \& Yakinin, E. (2011). SMART technologies and training materials. Hi-Tech at school, 3-4, 8-11.

Zeer, E. F. (2010). Personally-developing technologies of primary vocational education: textbook. Moscow, Russia: Publishing Center "Academy".

Zhang, Y., \& Lu, L.-W. (2008). Introducing Smart Structures Technology into Civil Engineering Curriculum: Education Development at Lehigh University. Journal of Professional Issues in Engineering Education and Practice, 134(1), 41-48.

Zhu, Z., Yu, M., \& Riezebos, P. (2016). A research framework of smart education. Smart Learning Environments, 3, 4. https://doi.org/10.1186/s40561-016-0026-2

Zulfiqar, A., \& Bhaskar, S. B. (2016). Basic statistical tools in research and data analysis. Indian Journal of Anaesthesia, 60(9), 662-669. http://dx.doi.org/10.4103/00195049.190623 